\section{Light-emitting Diode Light Transmission through Leaf Tissue of Seven Different Crops}

\author{
Gioia Massa ${ }^{1,2}$, Thomas Graham¹, Tim Haire, Cedric Flemming II, \\ Gerard Newsham, and Raymond Wheeler \\ National Aeronautics and Space Administration, Kennedy Space Center, \\ Merritt Island, FL 32899
}

Additional index words. anthocyanin, bioregenerative life support, canola, chlorophyll content, controlled-environment plant production, cucumber, intracanopy, lettuce, pepper, radish, soybean

\begin{abstract}
Significant advances in controlled-environment (CE) plant production lighting have been made in recent years, driven by rapid improvements in light-emitting diode (LED) technologies. Aside from energy efficiency gains, LEDs offer the ability to customize the spectrum delivered to a crop, which may have untold benefits for growers and researchers alike. Understanding how these specific wavebands are attenuated by plant tissue is important if lighting engineers are to fully optimize systems for $\mathrm{CE}$ plant production. In this study, seven different greenhouse and field crops (radish, Raphanus sativus 'Cherry Bomb II'; red romaine lettuce, Lactuca sativa 'Outredgeous', green leaf lettuce, Lactuca sativa 'Waldmann's Green'; pepper, Capsicum annuum 'Fruit Basket'; soybean, Glycine max 'Hoyt'; cucumber, Cucumis sativus 'Spacemaster'; canola, Brassica napus 'Westar') were grown in CE chambers under two different light intensities (225 and $\left.420 \mu \mathrm{mol} \cdot \mathrm{m}^{-2} \cdot \mathrm{s}^{-1}\right)$. Intact, fully expanded upper canopy leaves were used to determine the level of light transmission, at two to three different plant ages, across seven different wavebands with peaks at $400,450,530,595,630,655$, and $735 \mathrm{~nm}$. The photosynthetic photon flux (PPF) environment that plants were grown in affected light transmission across the different LED wavelengths in a crop-dependent manner. Plant age had no effect on light transmission at the time intervals examined. Specific waveband transmission from the seven LED sources varied similarly across plant types with low transmission of blue and red wavelengths, intermediate transmission of green and amber wavelengths, and the highest transmission at the far-red wavelengths. Higher native $P P F$ increased anthocyanin levels in red romaine lettuce compared with the lower native $P P F$ treatment. Understanding the differences in light transmission will inform the development of novel, energy-saving lighting architectures for $\mathrm{CE}$ plant growth.
\end{abstract}

Providing the optimal quality, quantity, and distribution of light in CE plant production, including bioregenerative life support systems and vertical farming applications, arguably remains the most significant hurdle in realizing the full economic and research potential of these systems. Electric lamps such as fluorescent, high-pressure sodium (HPS), and metal halide (MH) have been used for decades to grow plants in controlled environments (Sager and McFarlane, 1997; Wheeler, 2008). Typically, HPS and MH lamps are

\footnotetext{
Received for publication 20 Oct. 2014. Accepted for publication 24 Nov. 2014

Support for this work was provided through the Florida Space Grant Consortium, Oak Ridge Associated Universities (ORAU) NASA Post-Doctoral Research Fellowship Program, Kennedy Space Center (Gioia Massa; Thomas Graham), and Orbital Technologies Corporation (ORBITEC) Madison, WI (LED supplier). Cedric Flemming was supported through the NASA CIPAIR program.

We thank Larry Koss for help with plant chamber maintenance and light stand assembly.

${ }^{1}$ Co-first authors.

${ }^{2}$ To whom reprint requests should be addressed; e-mail gioia.massa@nasa.gov.
}

high-powered (e.g., 400 to $1000 \mathrm{~W}$ ) and act as relative "point" sources that can create light distribution challenges (Cathey and Campbell, 1980). Depending on the lamp and ballast type, these arc-discharge lamps can have a relatively short operational life [e.g., less than $5000 \mathrm{~h}$ for very high output (VHO) fluorescent; up to $\approx 25,000 \mathrm{~h}$ for HPS], which translates to high operation and maintenance costs. Furthermore, these lamps have a fixed spectral output, not accounting for any degradation over time, and the spectral quality cannot, in any practical sense, be altered through the cropping cycle (Cathey and Campbell, 1980).

LEDs are currently one of the most promising technologies for CE plant lighting systems (Massa et al., 2008) and especially for space crop growth applications (Barta et al., 1992; Massa et al., 2007; Mitchell, 2012; Olle and Viršile, 2013; Poulet et al., 2014). Compared with traditional arc-discharge lamps, LEDs have exceptionally long operational life expectancies (e.g., 50,000 to 100,000 h) (Yeh and Chung, 2009). Furthermore, LEDs operate at lower temperatures, emit comparably little long wave radiation, are intrinsically safer from a workplace safety perspective, and lend themselves to a wide range of system designs (Morrow, 2008; Olle and Viršile, 2013). Perhaps most important commercially, current state-of-the-art red and blue LEDs have efficiencies that approach or exceed $40 \%$ to $50 \%$, which is a significant improvement from where they were just 10 years ago (Bourget, 2008; Haitz and Tsao, 2011). Because LEDs have a relatively narrow spectral output, use of different colored LEDs also offers the potential for creating or changing spectral combinations throughout the growth cycle (Morrow, 2008; Yeh and Chung, 2009). Light-emitting diodes are easily configured into different form factors and, for example, have been used to provide intracanopy lighting where whole plant canopies can be irradiated from both above and from within (Gómez et al., 2013; Lu et al., 2012; Massa et al., 2005; Olle and Viršile, 2013; Trouwborst et al., 2010). Such intracanopy approaches need further research to develop adaptable concepts for a variety of crops and production systems, and hence overhead lighting systems will likely remain the preferred approach for CE crop production for some time.

Plants are capable of absorbing photons throughout the photosynthetically active radiation $(P A R)$ waveband (McCree, 1971) but it is has long been understood that as a result of chlorophyll, absorption in the blue and red regions is particularly strong (McCree, 1971; Rabideau et al., 1946). Ancillary photosynthetic pigments (e.g., carotenoids) are capable of absorbing wavelengths between these red and blue bands; the energy captured by these ancillary pigments can be transferred to the photosynthetic reaction centers (Salisbury and Ross, 1992). Because other wavelengths are not as readily absorbed as red and blue, the potential exists for greater flux of these wavelengths through the upper canopy leaves (Kim et al., 2004; Moss and Loomis, 1952; Rabideau et al., 1946; Wang and Folta, 2013). Lower attenuation of these wavelengths would allow penetration deeper into the canopy where they would contribute to the overall photosynthetic capacity of the plant through their absorption by lower canopy leaves.

The degree of light transmission into the canopy is determined by a range of factors including crop type, leaf age, leaf morphology, canopy architecture, and angle of incident light (Larcher, 1975; Monteith and Unsworth, 2007). Erectophile grasses, for example, have highly inclined leaves that allow light to penetrate directly, or by reflectance, deep into the canopy relative to species with more planophile leaf angle distributions (e.g., pepper) (Larcher, 1975). Although general leaf geometry (size, shape, and arrangement) is of primary importance in determining the light extinction coefficient for a plant canopy, spectral quality or composition can also have a significant influence (McCree, 1971; Monteith and Unsworth, 2007; Niinemets, 2010). This is generally not a concern in field crop production where plants are grown under broad-spectrum sunlight. When production is moved to a $\mathrm{CE}$ facility where light is delivered, in whole or part, by electric lighting systems, then the 
influence of spectral composition needs to be considered, especially in the case of narrow band lighting technologies such as LEDs.

Manipulating canopy light attenuation characteristics at different wavelengths could be a mechanism to purposefully deliver additional light to the inner canopy to improve production while reducing overall energy use. More generally, the manipulation of the incident light can be used to modify the phenotype of the plant, so-called environmentally modified organisms, to meet the requirements of the grower and/or consumer (Carvalho and Folta, 2014). Understanding how specific wavebands from sources like LEDs are absorbed, transmitted, and reflected by the canopy is critical if this type of manipulation is to be effective (Folta and Childers, 2008). A thorough understanding could allow researchers to develop "light recipes," using tunable LED systems, in much the same way nutrient recipes are managed. This approach could lead to improvements in overall canopy production without the cost and complexity of an intracanopy lighting system. The potential for improved production or altered morphology through better light penetration would come at little additional overall cost, because the lighting fixtures could be easily customized to desired photon compositions.

The objective of this study was to quantify light transmission through the leaf tissue of seven different crop types possessing a range of leaf morphologies, growth habits, and secondary metabolic characteristics that may influence light transmission, at seven waveband peaks spanning 400 to $735 \mathrm{~nm}$, using LED light sources. Additionally, the influence of the native light environment (high vs. low) on leaf light transmission was examined. The effects of leaf angle distributions and reflectance are not considered.

\section{Materials and Methods}

Growth chamber conditions. Plants were grown in a CE chamber (Environmental Growth Chambers, EGC M-48, Chagrin Falls, OH) with eight 400-W HPS and eight 400-W MH high-intensity discharge lamps evenly distributed across the light canopy. The chamber was maintained at a 16-h photoperiod with a $24 / 20{ }^{\circ} \mathrm{C}$ day/night temperature profile, constant relative humidity of $65 \%$, and $400 \mathrm{ppm} \mathrm{CO}_{2}$. Half of the chamber was outfitted with a neutral density screen filter, which reduced incident $P P F$ levels to $225 \pm 8 \mu \mathrm{mol} \cdot \mathrm{m}^{-2} \cdot \mathrm{s}^{-1}$ at bench height (low light treatment). The other half of the chamber remained at full intensity, which was $420 \pm 20 \mu \mathrm{mol} \cdot \mathrm{m}^{-2} \cdot \mathrm{s}^{-1}$ (high light treatment).

Plant material preparation. Seeds of radish (Raphanus sativus 'Cherry Bomb II'), lettuce (Lactuca sativa 'Outredgeous' and 'Waldmann's Green'), pepper (Capsicum annuum 'Fruit Basket'), soybean (Glycine max 'Hoyt'), cucumber (Cucumis sativus 'Spacemaster'), and canola (Brassica napus 'Westar') were sown in $15-\mathrm{cm}$ round pots. Pots contained a Nitex ${ }^{\circledR}$ nylon liner (Sefar Nytal PA-25-63, Sefar, Heiden, Switzerland) that held $2.5 \mathrm{~cm}\left(250 \mathrm{~cm}^{3}\right)$ arcillite, which was covered by $1300 \mathrm{~cm}^{3}$ of a 7:3 mixture of Fafard 2B (Conrad Fafard Inc., Agawam, MA) and arcillite (sifted greater than $2 \mathrm{~mm}$; Turface Proleague; Profile LLC, Buffalo Grove, IL) with Nutricote 18-6-8 time-release fertilizer (Type 180; Florikan, Sarasota, FL) incorporated at $7.5 \mathrm{~g} \cdot \mathrm{L}^{-1}$ dry medium. Six pots (three for each treatment) of each of the seven crop types examined were prepared with five seeds sown in each pot to ensure successful and uniform seedling establishment.

Lettuce and radish plants were harvested before the larger growing pepper and soybean crops. Harvest of the early-maturing lettuce and radish crops allowed for the inclusion of two additional crop types, cucumber and canola, which were selected based on leaf morphology and time required to reach full size. All plants were allowed to grow until reaching their full anticipated height with numerous, fully expanded leaves available for testing.

Plants were placed in covered subirrigation trays, which had evenly spaced holes cut in the covers to accommodate $15-\mathrm{cm}$ diameter pots. The water level in each tray was maintained at a depth of 1 to $2 \mathrm{~cm}$ using deionized water. There were a total of three trays in each $P P F$ treatment zone for a total of six trays in the chamber. Each crop type was represented in each tray. Plants within a single tray were systematically rotated through the tray every $2 \mathrm{~d}$ to reduce position effects in the chamber. Once sufficient numbers of seedlings had emerged so that plant selection could be made based on seedling uniformity across the replicates, soybean and canola plants were thinned to one plant per pot. Lettuce, pepper, and cucumber were thinned to two plants per pot, whereas the radishes were thinned to three plants per pot.

Transmittance apparatus. Seven single waveband LED modules (Fig. 1), with associated passive heat sinks, had a waveband with (manufacturer-specified; measured peaks in parentheses) the peak centered at $400(405) \mathrm{nm}$ (violet), 450 (444) nm (blue), $530(533) \mathrm{nm}$ (green), 595 (597) nm (amber), 630 (631) $\mathrm{nm}$ (orange-red), 655 (660) nm (red), or 735 (742) nm (far-red) (Orbital Technologies Corporation, Madison, WI; Yano and Fujiwara, 2012). A test stand was constructed on which the LED modules were mounted facing down (i.e., LED face oriented parallel to the bench surface). This orientation simplified the movement of plants (leaves remained attached to the plant) between individual modules, the change out of leaf samples between replicate trials, and the collection of transmittance data. Each module was independently powered in a current-controlled mode (12 VDC; $350 \mathrm{~mA}$ nominal, 500 to $750 \mathrm{~mA}$ maximum depending on module), which eliminated potential light interference from neighboring modules. All measurements were made in an otherwise dark room.

Transmission measurements. Light transmission measurements were collected with and without (blank reference) a leaf in the beam path using a spectroradiometer (StellarNet EPP-200C spectroradiometer; Apogee Instruments, Logan, UT). The sensor was mounted on a laboratory scissor lift with the sensor maintained $10 \mathrm{~cm}$ below the individual light source. The sensor assembly was placed under each LED module and adjusted so that the sensor was level with the light source and the leaf sample was $10 \mathrm{~cm}$ from the LED module face. A blank reference measurement was taken immediately before the sample measurement. Light transmittance measurements were made on individual, mature, fully expanded leaves that remained attached to the parent plant. Each leaf was placed atop the sensor head and secured in place. The leaf was positioned on the sensor

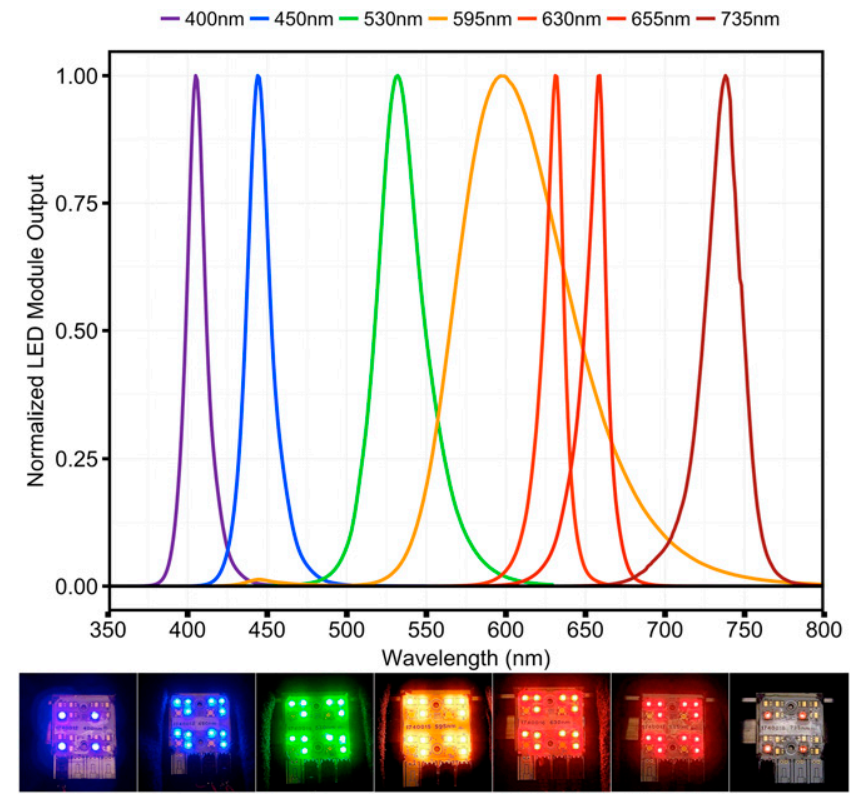

Fig. 1. Normalized spectra of the seven light-emitting diode (LED) modules used for transmission measurements. Individual illuminated LED modules are shown for reference. 
such that the tissue covering the actual sensing element had minimal vasculature and was free of any damage. Three plants $(n=3)$ of each crop type were selected from each of the two light regimes. Three separate leaf subsamples were selected from each of these plants for transmittance measurements. All measurements for a given crop type were taken during the same sampling session. Measurements were repeated twice over the course of the growth cycle with the exception of the pepper plants, which were measured at a third point during the growth cycle. The transmitted radiation for each leaf was obtained by integrating the total light passing through the leaf at the specific peak wavelength $\pm 100 \mathrm{~nm}$ (e.g., for the 400-nm LED module, a scan from 300 to $500 \mathrm{~nm}$ was conducted). This value was then compared with the blank reading (i.e., no leaf in the beam path) to calculate the percent transmission.

Leaf chlorophyll analysis. After light transmission measurements, all plants were returned to the $\mathrm{CE}$ chamber. After final light transmission measurements, analysis of leaf chlorophyll content was performed as per Richardson et al. (2002). Briefly, three fully mature leaves from each plant were selected and leaf discs (one per leaf) excised with a \#3 punch $\left(0.442 \mathrm{~cm}^{2}\right)$. Discs were immediately weighed and placed in a foil-wrapped vial containing $10 \mathrm{~cm}^{3}$ dimethylsulfoxide (DMSO). Vials were capped and placed in a $70{ }^{\circ} \mathrm{C}$ forced-air oven to facilitate extraction. After 3 to $12 \mathrm{~h}$, vials were removed and allowed to return to room temperature. Aliquots were drawn from each vial and placed in a quartz cuvette. The samples were placed in a spectrophotometer (DU 800; Beckman Coulter, Miami, FL) previously blanked with clean DMSO and the absorbance was measured at $645 \mathrm{~nm}$ and $663 \mathrm{~nm}$. Chlorophyll concentration was calculated according to (Arnon, 1949):

Chl a $(\mathrm{g} / \mathrm{L})=0.0127 \mathrm{~A}_{663}-0.00269 \mathrm{~A}_{645}$
$\operatorname{Chl~b}(\mathrm{g} / \mathrm{L})=0.0029 \mathrm{~A}_{663}-0.00468 \mathrm{~A}_{645}$
$\operatorname{Total~Chl~}(\mathrm{g} / \mathrm{L})=0.0202 \mathrm{~A}_{663}+0.00802 \mathrm{~A}_{645}$

Using the chlorophyll content and the leaf sample area, an estimate of the chlorophyll content per unit area $\left(\mathrm{mg} \cdot \mathrm{m}^{-2}\right)$ was calculated.

Anthocyanin levels in red romaine lettuce. Anthocyanin levels were measured in the lettuce cultivar Outredgeous based on a modified procedure from Stutte et al. (2009). Briefly, two tissue samples of $1 \mathrm{~g}$ each were taken from mature fully expanded leaves from each lettuce plant. Samples were flash frozen in $15-\mathrm{cm}^{3}$ centrifuge tubes using liquid nitrogen and ground in the tube using a spatula. Aliquots $\left(10 \mathrm{~cm}^{3}\right)$ of acidified methanol (1\% hydrochloric acid:99\% methanol) were added to each tube and the samples were then blended with a vortex mixer. When samples were not being manipulated, they were stored in a $-20{ }^{\circ} \mathrm{C}$ freezer. Samples were transferred to $50-\mathrm{cm}^{3}$ centrifuge tubes, placed in a chilled centrifuge $\left(2{ }^{\circ} \mathrm{C}\right)$, and centrifuged at $3000 \mathrm{RPM}$ for $10 \mathrm{~min}$. The supernatant was decanted to labeled tubes and stored in the dark. The pellet was re-suspended in an additional $10 \mathrm{~cm}^{3}$ acidified methanol. Blending and centrifugation were repeated, and supernatant fractions were combined. Extract solution was brought to $25 \mathrm{~cm}^{3}$ with acidified methanol and $0.8 \mathrm{~cm}^{3}$ of the final solution was pipetted to disposable $1-\mathrm{cm}^{3}$ polystyrene cuvettes. Absorbance readings were taken at $530 \mathrm{~nm}$ and $650 \mathrm{~nm}$ with a spectrometer (Beckman Coulter DU 730, Brea, CA). As a result of the intensity of the solution for the high light-grown plants, a second run was conducted with a $50 \%$ dilution $\left(0.4 \mathrm{~cm}^{3}\right.$ of extract and $0.4 \mathrm{~cm}^{3}$ of acidified methanol). The $650-\mathrm{nm}$ reading was used to correct for interference by chlorophyll. Calculations of anthocyanin levels per gram of fresh tissue from absorbance measurements were based on a standard curve of kuromanin chloride in extraction solvent with compensation for dilution.

Extinction coefficient determination. To determine light extinction coefficients (EC) for each of the wavelengths $\left(k_{\lambda}\right)$, light penetration percentages were converted to fractions, which were then related to leaf area index (LAI) using the equation $\mathrm{I} / \mathrm{I}_{0}=\mathrm{e}^{-k} \lambda^{\cdot \mathrm{LAI}}$, where $I$ is the intensity of radiation transmitted through the leaf tissue; $\mathrm{I}_{0}$ is the incident radiation at the leaf surface; $\mathrm{k}_{\lambda}$ is the $\mathrm{EC}$ at a specific wavelength; and LAI is the LAI for the setup, which in this case, there is only one layer of leaf tissue, which gives a LAI $=1$ (Kasanaga and Monsi, 1954; Larcher, 1975). Taking the natural $\log$ of the data points as fractions of light transmitted solves for $\mathrm{k}_{\lambda}$ for each crop type at each different waveband.

Data analysis. Statistical analysis was done using R (R Core Team, 2013) and the mixed effects package lme 4 (Bates, 2014). A linear mixed effects analysis of the relationship between the native light environment and light transmission at different wavelengths was conducted. Interactions were limited to the native light environment and transmission wavelength. The $P$ values were obtained using likelihood ratio tests of the full model including the effect variable in question against the reduced model. Where the light treatment effect was not significant, the transmission data variance was checked for consistency between the treatments and the data pooled where appropriate. Transmission levels between wavelengths were compared on the pooled data. No between-crop type comparisons were conducted for transmission. A two-way analysis of variance was conducted for chlorophyll and specific leaf area using GraphPad Prism (Version 6.00 for Mac; GraphPad Software, La Jolla, CA; $<$ http://www.graphpad.com $>$ ) followed by Tukey's multiple comparisons. A two-tailed $t$ test (GraphPad Prism) was used to compare anthocyanin levels in Lactuca sativa cv. Outredgeous.

\section{Results and Discussion}

Light transmission and response to the light environment. The native light environment under which the crops were grown affected the transmission of light through the leaf tissue in four of seven crop types (Table 1; Fig. 2). Radish, pepper, red lettuce, and canola all exhibited different transmission levels between the high and low light growth conditions in at least three of the seven wavelengths examined (Table 1). These crops also exhibited differences in transmission levels between the different wavelengths measured within each native light environment (Fig. 2A-D). Green lettuce, cucumber, and soybean did not exhibit any significant differences between the native light levels; in these crops, the pooled transmission data are presented (Fig. 3A-C). In all crops, the transmission of $400 \mathrm{~nm}$ and $450 \mathrm{~nm}$ light was less than 5\%. Far-red radiation $(735 \mathrm{~nm})$ passed through the leaves with transmission levels ranging from $42.2 \%$ to $64.9 \%$. The transmission at the remaining wavelengths ranged between $5 \%$ and $25 \%$ (Figs. 2A-D and 3A-C). In no case did the age of the plant, measured as days after planting, affect the transmission at any wavelength (data not shown). Although no differences were detected in fully mature leaves at the time differentials examined, transmission could vary over the full life of the leaf as a result of changes in chlorophyll content and other pigments as the leaf ages and is shaded by newer leaves (Carter and Knapp, 2001; Roberts et al., 1998). Further evaluation of age-dependent transmission, over a broader age range than examined here, would be of interest.

Table 2 shows overall average values for the $k_{\lambda}$ with all data pooled for crop type and times. Average $\mathrm{k}_{\lambda}$ for LED light passing through the leaves ranged from 2.01 at $530 \mathrm{~nm}$ to 4.12 at $400 \mathrm{~nm}$ within the $P A R$ band, whereas the $k_{\lambda}$ value for far-red $735 \mathrm{~nm}$ light passing through leaves was 0.65 (Table 2).

As expected, the red and blue wavelengths were quickly attenuated by leaves of all the crop types examined, corresponding to high light $\mathrm{k}_{\lambda}$ at those wave bands (Table 2). Also as expected, green and amber light penetrated the leaves better than the red and blue wavelengths with $\mathrm{k}_{\lambda}$ slightly greater than 2 (McCree, 1971; Moss and Loomis, 1952). The far-red radiation penetrated leaves the greatest and showed the lowest EC $\left(\mathrm{k}_{\lambda}=0.65\right)$. This was also expected based on the literature (Larcher, 1975). Far-red radiation is an environmental cue along with attenuated blue light that plants often use to detect shaded environments, typically stimulating internode elongation in pursuit of better light environments (Larcher, 1975; Salisbury and Ross, 1992).

In four of the seven crops examined, the plants grown under the higher light environment tended to transmit less light across most of the midrange wavelengths than plants grown under lower light (Table 1; Fig. 2). Much of this could be the result of intrinsic differences in leaf mesophyll and other aspects of leaf anatomy between the higher and lower PPF environments (Boardman, 1977), although in this study only radish exhibited a $P P F$ effect on leaf chlorophyll content (Fig. 4). The greater transmittance of 
Table 1. Percent transmittance of light as influenced by native light environment for the leaves of four crop types in which a light treatment effect was detected.

\begin{tabular}{|c|c|c|c|c|c|c|}
\hline \multirow{3}{*}{$\frac{\text { Crop type }}{\text { Radish }}$} & \multirow{3}{*}{$\begin{array}{c}\text { Wavelength } \\
\text { (nm) }\end{array}$} & \multicolumn{4}{|c|}{ Light level } & \multirow{2}{*}{$\begin{array}{c}\text { Significance } \\
\text { level }^{v}\end{array}$} \\
\hline & & \multicolumn{2}{|c|}{ High $^{2}$} & \multicolumn{2}{|c|}{ Low $^{y}$} & \\
\hline & & $2.779^{x}$ & $\pm 0.104^{w}$ & 2.266 & \pm 0.129 & NS \\
\hline & 450 & 1.618 & \pm 0.171 & 2.653 & \pm 0.135 & NS \\
\hline & 530 & 10.430 & \pm 0.414 & 13.543 & \pm 0.320 & $* * *$ \\
\hline & 595 & 6.796 & \pm 0.317 & 9.849 & \pm 0.438 & $* * *$ \\
\hline & 630 & 4.627 & \pm 0.317 & 6.868 & \pm 0.369 & $* *$ \\
\hline & 655 & 3.454 & \pm 0.241 & 3.796 & \pm 0.279 & NS \\
\hline & 735 & 45.959 & \pm 0.943 & 48.636 & \pm 0.733 & $* * *$ \\
\hline \multirow[t]{7}{*}{ Pepper } & 400 & 0.670 & \pm 0.070 & 0.788 & \pm 0.051 & NS \\
\hline & 450 & 0.689 & \pm 0.029 & 0.917 & \pm 0.039 & NS \\
\hline & 530 & 7.286 & \pm 0.081 & 13.814 & \pm 1.335 & $* * *$ \\
\hline & 595 & 5.012 & \pm 0.183 & 8.743 & \pm 0.194 & * \\
\hline & 630 & 2.819 & \pm 0.376 & 5.458 & \pm 0.112 & NS \\
\hline & 655 & 1.260 & \pm 0.114 & 3.007 & \pm 0.188 & NS \\
\hline & 735 & 43.619 & \pm 0.803 & 49.540 & \pm 2.579 & $* * *$ \\
\hline \multirow[t]{7}{*}{ Red Lettuce } & 400 & 1.292 & \pm 0.112 & 2.855 & \pm 0.169 & NS \\
\hline & 450 & 2.351 & \pm 0.418 & 3.473 & \pm 0.061 & NS \\
\hline & 530 & 9.667 & \pm 1.019 & 20.214 & \pm 0.752 & $* * *$ \\
\hline & 595 & 13.211 & \pm 0.342 & 18.297 & \pm 0.450 & $* * *$ \\
\hline & 630 & 13.168 & \pm 0.369 & 17.300 & \pm 0.361 & $* * *$ \\
\hline & 655 & 9.676 & \pm 0.873 & 11.370 & \pm 0.190 & NS \\
\hline & 735 & 60.138 & \pm 0.122 & 49.540 & \pm 0.329 & $* * *$ \\
\hline \multirow[t]{7}{*}{ Canola } & 400 & 0.642 & \pm 0.106 & 1.124 & \pm 0.032 & NS \\
\hline & 450 & 0.777 & \pm 0.109 & 1.619 & \pm 0.444 & NS \\
\hline & 530 & 9.672 & \pm 0.508 & 13.647 & \pm 1.328 & $* *$ \\
\hline & 595 & 7.021 & \pm 0.307 & 10.519 & \pm 0.980 & $* *$ \\
\hline & 630 & 5.982 & \pm 1.127 & 6.439 & \pm 0.267 & NS \\
\hline & 655 & 2.480 & \pm 0.691 & 3.182 & \pm 0.314 & NS \\
\hline & 735 & 47.225 & \pm 0.549 & 54.939 & \pm 0.570 & $* * *$ \\
\hline
\end{tabular}

${ }^{2} 420 \pm 20 \mu \mathrm{mol} \cdot \mathrm{m}^{-2} \cdot \mathrm{s}^{-1}$.

${ }^{\mathrm{y}} 225 \pm 8 \mu \mathrm{mol} \cdot \mathrm{m}^{-2} \cdot \mathrm{s}^{-1}$.

${ }^{\mathrm{x}} \mathrm{n}=3$.

${ }^{\mathrm{w}} \mathrm{SE}$.

'Mean separation through Tukey's multiple comparison test.

Ns, ${ }^{*}, * *, * *$ Nonsignificant or significant at $P \leq 0.05,0.01$, or 0.001 , respectively

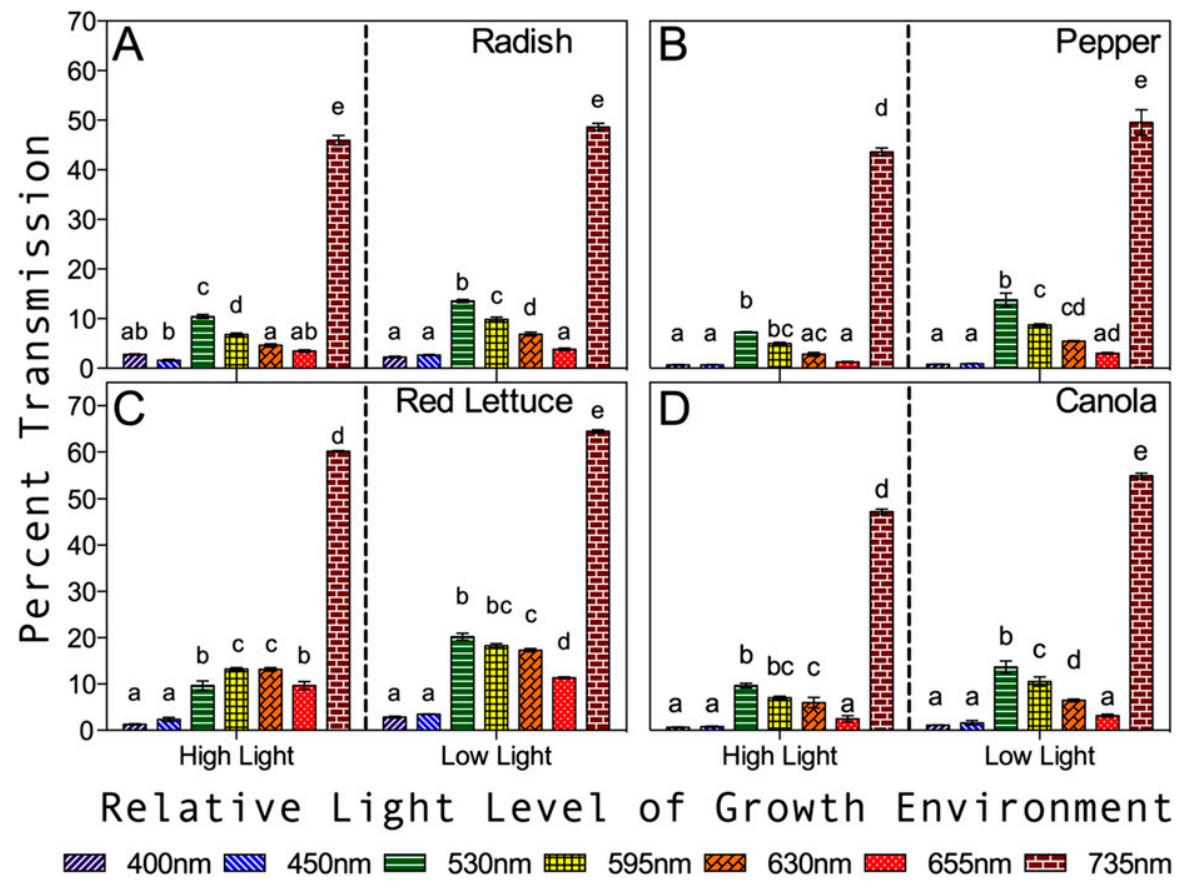

Fig. 2. Within-treatment (light intensity) percent transmission at 400, 450, 530, 595, 630, 655, and $735 \mathrm{~nm}$ for crops grown at two different native light intensities (high: $420 \pm 20 \mu \mathrm{mol} \cdot \mathrm{m}^{-2} \cdot \mathrm{s}^{-1}$ and low: $\left.225 \pm 8 \mu \mathrm{mol} \cdot \mathrm{m}^{-2} \cdot \mathrm{s}^{-1}\right)$ and showing a light treatment effect. Transmission levels for: (A) radish (Raphanus sativus 'Cherry Bomb II'), (B) pepper (Capsicum annuum 'Fruit basket'), (C) red lettuce (Lactuca sativa 'Outredgeous'), and (D) canola (Brassica napus 'Westar') at each waveband examined. Bars within each light treatment with the same letter do not differ at $\alpha=$ 0.05. Error bars are SEM.

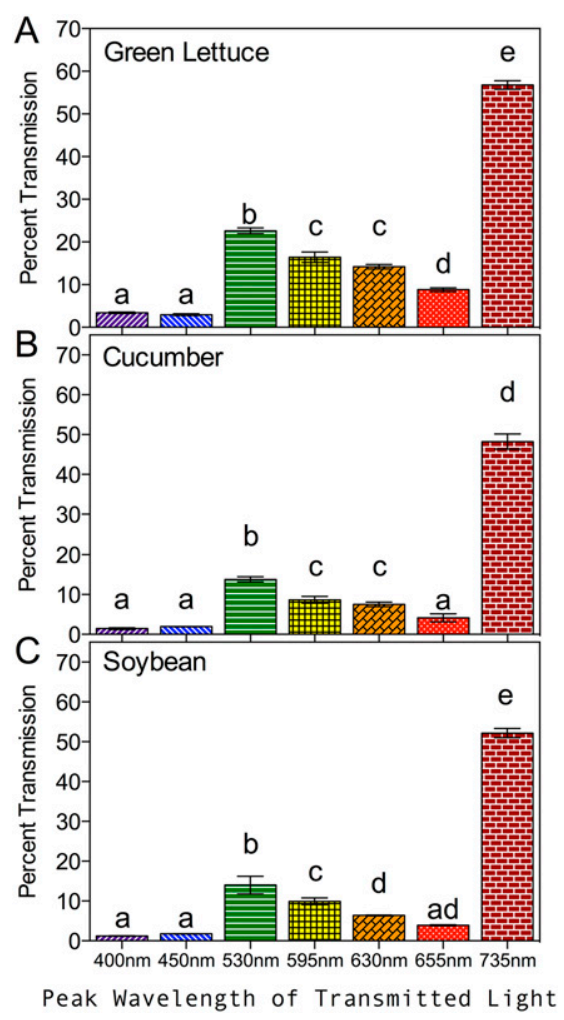

Fig. 3. Percent transmission at 400, 450, 530, 595, 630,655 , and $735 \mathrm{~nm}$ for crops grown at two different native light intensities (high: $420 \pm 20$ $\mu \mathrm{mol} \cdot \mathrm{m}^{-2} \cdot \mathrm{s}^{-1}$ and low: $\left.225 \pm 8 \mu \mathrm{mol} \cdot \mathrm{m}^{-2} \cdot \mathrm{s}^{-1}\right)$ in which no light treatment effect was detected. Transmission levels for (A) green lettuce ( $\mathrm{Lac}$ tuca sativa 'Waldmann's Green') (B) cucumber (Cucumis sativus 'Spacemaster'), (C) soybean (Glycine max 'Hoyt'). Data are presented as pooled values with comparisons made between wavelengths. Bars with the same letter do not differ at $\alpha=0.05$. Error bars are SEM.

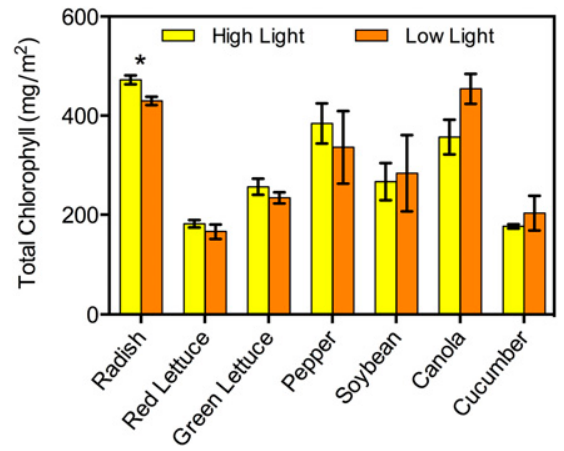

Fig. 4. Chlorophyll content for the seven crop types examined. There were no significant differences between the light environments for any of the crop types, except for radish $(P=0.031)$. Error bars are SEM.

green and amber-colored light in general (Table 1; Figs. 2 and 3) suggests that these wavelengths should penetrate plant canopies more effectively than red and blue light alone. The exclusive use of dichromatic red-blue light sources such as those typically proposed for LED-based sole-source photosynthesis lighting may be a concern for deep 
Table 2. Average extinction coefficients $\left(\mathrm{k}_{\lambda}\right)$ at each waveband across all crop types ${ }^{\mathrm{z}}$ and sampling periods ${ }^{\mathrm{y}}$ for each wavelength.

\begin{tabular}{lcccccc}
\hline \multicolumn{5}{c}{ Waveband peak $(\mathrm{nm})$} \\
\hline $400 \mathrm{~nm}$ & $450 \mathrm{~nm}$ & $530 \mathrm{~nm}$ & $595 \mathrm{~nm}$ & $630 \mathrm{~nm}$ & $655 \mathrm{~nm}$ & $735 \mathrm{~nm}$ \\
4.12 & 4.03 & 2.01 & 2.26 & 2.51 & 3.02 & 0.65 \\
\hline
\end{tabular}

${ }^{2}$ Radish ('Cherry Bomb II'), lettuce ('Outredgeous' and 'Waldmann's Green'), pepper ('Fruit basket'), soybean ('Hoyt'), cucumber ('Spacemaster'), and canola ('Westar').

${ }^{\mathrm{y}}$ Transmission measurements and associated $\mathrm{k}_{\lambda}$ calculations were made on two to three separate occasions, typically separated by 7 to $10 \mathrm{~d}$, for each species.

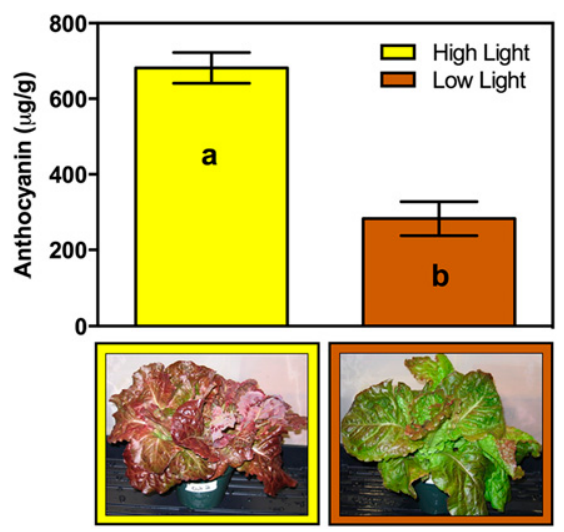

Fig. 5. Anthocyanin content of red lettuce (Lactuca sativa 'Outredgeous') as influenced by light intensity under which the plants were grown. Mean anthocyanin concentrations are significantly different $(P=0.028)$ between the high and low light environments. Representative high light (left) and low light (right) treated plants are presented as visual indicators of the effect. Error bars are SEM.

canopies with planophile leaves (e.g., bell pepper, tomato, bean). Without wavelengths that can penetrate deeper into the canopy to sustain photosynthesis and participate in other light-mediated reactions, there is potential for physiological and productivity implications (Kim et al., 2004; Lu et al., 2012; Wang and Folta, 2013).

Green light is effective $P A R$ if it is absorbed, and one might hypothesize that including green light in the spectrum could sustain deeper canopy profiles than with just red or blue alone (Kim et al., 2004; Lu et al., 2012; Wang and Folta, 2013). The degree of penetration for far-red was striking, yet radiation at this wavelength does not contribute significantly to photosynthesis. It would however have a significant influence on leaf development through alterations in red/far-red ratios in the lower canopy and overall phytochrome-mediated events (Folta and Childers, 2008).

Anthocyanin levels. 'Outredgeous' lettuce plants growing under high-light conditions were darker red and had thicker, smaller, and more waxy leaves than those grown under low light (Fig. 5). This red coloration corresponded to an average 2.5 -fold increase in anthocyanin level per gram of fresh tissue in the high light-treated plants vs. the low-light plants (Fig. 5).

Measurements of anthocyanin showed a clear increase when 'Outredgeous' lettuce plants were grown under higher light intensity
(Fig. 5). Higher anthocyanin concentration has the potential to affect light transmittance, and the "redder" high-light leaves did have lower transmittance than the greener, low-light leaves at all tested wavelengths (Table 1). However, this trend was observed in all crops that demonstrated a native light environment effect (Table 1; Fig. 2), indicating that the effect is not solely or even directly related to anthocyanin levels. This increase in anthocyanin does support other findings that higher light can promote more anthocyanin and antioxidant qualities of some plants (Stutte et al., 2009), a response that can be used to improve the nutritional quality of these crops.

As plant production capabilities are expanded, through CE agriculture, to unconventional locations such as Arctic and Antarctica research stations, the International Space Station, and future extraterrestrial planetary environments, LEDs will likely be the sole-source lighting systems used to power food production (Giroux et al., 2006; Massa et al., 2007; Zabel et al., 2014). Understanding and applying these wavelength-specific light transmission data to the development of new plant growth lighting designs could lead to significant energy savings and increased crop yields for long-duration plant growth in isolated environments. Better understanding of wavelength transmission could also benefit controlled and semicontrolled agriculture (e.g., environmentally responsive films/coverings and reflectors in high tunnels and greenhouses) and even open-field production (e.g., colored reflective mulches or colored shade netting).

The native light environment that the plants were grown under did affect transmission of specific wavelengths, but the pattern of transmission varied with crop type. Furthermore, in some cases, the native light environment did not seem to influence transmission at all. Greater native light intensity differentials may amplify the effects, but for typical growth chamber light environments such as those used here, the response was small and crop-dependent. The native light environment can impact pigmentation and by association could influence the nutritional quality of crops such as lettuce. This in turn can drive or contribute to grower decisions surrounding the selection and adoption of new lighting systems. The inclusion of additional wavelengths in LED-based plant lighting systems should be considered when designing and purchasing CE LED lighting systems, particularly in deep canopies with a planophile architecture.

\section{Literature Cited}

Arnon, D.I. 1949. Copper enzymes in isolated chloroplasts. Polyphenoloxidase in beta vulgaris. Plant Physiol. 24:1-15.

Barta, D.J., T.W. Tibbitts, R.J. Bula, and R.C. Morrow. 1992. Evaluation of light emitting diode characteristics for space-based plant irradiation source. Adv. Space Res. 12:141149.

Bates, D. 2014. Ime4: Linear mixed-effects models using Eigen and S4. R package Version 1.1-7.

Boardman, N.K. 1977. Comparative photosynthesis of sun and shade plants. Annu. Rev. Plant Physiol. 28:355-377.

Bourget, C.M. 2008. An introduction to lightemitting diodes. HortScience 43:1944-1946.

Carter, G.A. and A.K. Knapp. 2001. Leaf optical properties in higher plants: Linking spectral characteristics to stress and chlorophyll concentration. Amer. J. Bot. 88:677-684.

Carvalho, S.D. and K.M. Folta. 2014. Environmentally modified organisms - Expanding genetic potential with light. Crit. Rev. Plant Sci. 33:486-508.

Cathey, H.M. and L.E. Campbell. 1980. Light and lighting systems for horticultural plants. In: Janick, J. (ed.). Hort. Rev. 2:491-537.

Folta, K.M. and K.S. Childers. 2008. Light as a growth regulator: Controlling plant biology with narrow-bandwidth solid-state lighting systems. HortScience 43:1957-1964.

Giroux, R., A. Berinstain, S. Braham, T. Graham, M. Bamsey, K. Boyd, M. Silver, A. LussierDesbiens, P. Lee, M. Boucher, K. Cowing, and M.A. Dixon. 2006. Greenhouses in extreme environments: The Arthur Clarke Mars Greenhouse design and operation overview. Adv. Space Res. 38:1248-1259.

Gómez, C., R.C. Morrow, C.M. Bourget, G.D. Massa, and C.A. Mitchell. 2013. Comparison of intracanopy light-emitting diode towers and overhead high-pressure sodium lamps for supplemental lighting of greenhouse-grown tomatoes. HortTechnology 23:93-98.

Haitz, R. and J.Y. Tsao. 2011. Solid-state lighting: The case 10 years after and future prospects. Phys. Status Solidi A 208:17-29.

Kasanaga, H. and M. Monsi. 1954. On the lighttransmission of leaves, and its meaning for the production of matter in plant communities. Jap. J. Bot. 14:304-324

Kim, H.-H., G.D. Goins, R.M. Wheeler, and J.C. Sager. 2004. Green-light supplementation for enhanced lettuce growth under red- and bluelight-emitting diodes. HortScience 39:1617-1622.

Larcher, W. 1975. Physiological plant ecology Springer-Verlag, Heidelberg, Germany.

Lu, N., T. Maruo, M. Johkan, M. Hohjo, S. Tsukagoshi, Y. Ito, T. Ichimura, and Y. Shinohara. 2012. Effects of supplemental lighting within the canopy at different developing stages on tomato yield and quality of single-truss tomato plants grown at high density. Envrion. Control Biol. 50:1-11.

Massa, G.D., J.C. Emmerich, R.C. Morrow, C.M. Bourget, and C.A. Mitchell. 2007. Plant-growth lighting for space life support: A review. Gravitational Space Res. 19:19-30.

Massa, G.D., H.-H. Kim, R.M. Wheeler, and C.A. Mitchell. 2008. Plant productivity in response to LED lighting. HortScience 43:1951-1956.

Massa, G.D., C.A. Mitchell, J.C. Emmerich, and R.C. Morrow. 2005. Development of a reconfigurable led plant-growth lighting system for equivalent system mass reduction in an ALS 0 ed. Warrendale, PA: International Conference on Environmental Systems, SAE, Paper \#2005-01-2955.

McCree, K.J. 1971. The action spectrum, absorptance and quantum yield of photosynthesis in crop plants. Agr. Meteorol. 9:191-216. 
Mitchell, C.A. 2012. Plant lighting in controlled environments for space and earth applications. VII Intl. Symp. Light Hort. Systems 956.

Monteith, J. and M. Unsworth. 2007. Principles of environmental physics. 3rd Ed. Academic Press, Burlington, MA.

Morrow, R.C. 2008. LED lighting in horticulture. HortScience 43:1947-1950.

Moss, R.A. and W.E. Loomis. 1952. Absorption spectra of leaves. I. The visible spectrum. Plant Physiol. 27:370-391.

Niinemets, Ü. 2010. A review of light interception in plant stands from leaf to canopy in different plant functional types and in species with varying shade tolerance. Ecol. Res. 25:693-714.

Olle, M. and A. Viršile. 2013. The effects of lightemitting diode lighting on greenhouse plant growth and quality. Agr. Food Sci. 22:223234.

Poulet, L., G.D. Massa, R.C. Morrow, and C.M. Bourget. 2014. Significant reduction in energy for plant-growth lighting in space using targeted LED lighting and spectral manipulation. Life Sci. Space Res. 2:43-53.
R Core Team. 2013. R: A language and environment for statistical computing. R Foundation for Statistical Computing, Vienna, Austria.

Rabideau, G.S., C.S. French, and A.S. Holt. 1946. The absorption and reflection spectra of leaves, chloroplast suspensions, and chloroplast fragments as measured in an Ulbricht sphere. Amer. J. Bot. 33:769-777.

Richardson, A.D., S.P. Duigan, and G.P. Berlyn. 2002. An evaluation of noninvasive methods to estimate foliar chlorophyll content. New Phytol. 153:185-194.

Roberts, D.A., B.W. Nelson, J.B. Adams, and F. Palmer. 1998. Spectral changes with leaf aging in Amazon caatinga. Trees (Berl.) 12:315-325.

Sager, J.C. and J.C. McFarlane. 1997. Radiation, p. 1-29. In: Langhans, R.W. and T.W. Tibbitts (eds.). Plant growth chamber handbook. North Central Regional Res. Publ. No. 340, Iowa State Agr. Home Econ. Expt. Stat. Rpt. No. 99, Ames, IA.

Salisbury, F.B. and C.W. Ross. 1992. Plant physiology. 4th Ed. Wadsworth Pub. Co., Belmont, CA

Stutte, G.W., S. Edney, and T. Skerritt. 2009. Photoregulation of bioprotectant content of red leaf lettuce with light-emitting diodes. HortScience 44:79-82.

Trouwborst, G., J. Oosterkamp, S.W. Hogewoning, J. Harbinson, and W. van Ieperen. 2010. The responses of light interception, photosynthesis and fruit yield of cucumber to LED-lighting within the canopy. Physiol. Plant. 138:289-300.

Wang, Y. and K.M. Folta. 2013. Contributions of green light to plant growth and development. Amer. J. Bot. 100:70-78.

Wheeler, R.M. 2008. A historical background of plant lighting: An introduction to the workshop. HortScience 43:1942-1943.

Yano, A. and K. Fujiwara. 2012. Plant lighting system with five wavelength-band light-emitting diodes providing photon flux density and mixing ratio control. Plant Methods 8:46-58.

Yeh, N. and J.P. Chung. 2009. High-brightness LEDs-Energy efficient lighting sources and their potential in indoor plant cultivation. Renew. Sustain. Energy Rev. 13:2175-2180.

Zabel, P., M. Bamsey, D. Schubert, and M. Tajmar. 2014. Review and analysis of plant growth chambers and greenhouse modules for space. 44th Intl. Conf. Environ. Systems 44:1-17. 